\title{
Chromosomal and reproductive features of some Oriental and Australasian scale insects (Homoptera, Coccinea)
}

\author{
Ilya A. Gavrilov-Zimin' \\ I Zoological Institute, Russian Academy of Sciences, Universitetskaya nab. 1, St. Petersburg, 199034, Russia \\ Corresponding author: Ilya A. Gavrilov-Zimin (coccids@gmail.com)
}

Academic editor: V. G. Kuznetsova | Received 17 April 2020 | Accepted 5 July 2020 | Published 20 July 2020

http://zoobank.org/D2A1B8A1-B2EE-4251-8F36-66B295BA1B73

Citation: Gavrilov-Zimin IA (2020) Chromosomal and reproductive features of some Oriental and Australasian scale insects (Homoptera, Coccinea). Comparative Cytogenetics 14(3): 339-352. https://doi.org/10.3897/CompCytogen. v14i3.53367

\begin{abstract}
Fourteen species of scale insects from the families Margarodidae s.l., Pseudococcidae, Eriococcidae, and Coccidae were investigated for the first time in respect to karyotypes, genetic systems, modes of reproduction and general anatomy of the female reproductive system. One of the studied species, Steatococcus samaraius Morrison, 1927, showed hermaphroditic reproduction of the female-like specimens, the other species demonstrated bisexual reproduction with a peculiar "Lecanoid" heterochromatinization of the paternal set of chromosomes in male embryos or thelytocous parthenogenesis. Antonina parazonata Williams, 2004 and Saccharolecanium krugeri (Zehntner, 1897) are recorded here for the first time from Thailand, Antonina vietnamensis Williams, 2004 and Geococcus satellitum Williams, 2004 - for the first time from Laos.
\end{abstract}

\section{Keywords}

scale insects, giant scales, mealybugs, soft scales, felt scales, chromosome number, karyotype, genetic system, reproductive system

\section{Introduction}

The present paper continues a series of the author's publications on the cytogenetics and reproductive biology of scale insects from different regions of the world (Gavrilov 2004, 2007, Gavrilov and Kuznetsova 2007, Gavrilov and Trapeznikova 2007, 2008, 2010, Gavrilov-Zimin 2011, 2012, 2016, 2017, 2018a, b, Gavrilov-Zimin et al. 2015).

Copyright llya A. Gavrilov-Zimin. This is an open access article distributed under the terms of the Creative Commons Attribution License (CC BY 4.0), which permits unrestricted use, distribution, and reproduction in any medium, provided the original author and source are credited. 
Here, 14 previously unstudied species from 13 genera of the families Margarodidae s.l., Pseudococcidae, Eriococcidae, and Coccidae are considered in respect of their karyotypes, genetic systems, modes of reproduction, and general anatomy of the female reproductive system. Unusual aberrant genetic systems of scale insects have been reviewed several times previously (e.g., Hughes-Schrader 1948, Nur 1980, Gavrilov 2007, Gavrilov-Zimin et al. 2015) and will not be discussed here. General evolutionary aspects of scale insect reproductive biology and ontogenesis were analyzed in a special monograph (Gavrilov-Zimin 2018a), that can also be used by readers for the clarifying of the terminology and the higher-level taxa system, explored below.

General anatomic types of the female reproductive system in the scale insects were previously reviewed by De Marzo et al. (1990) basing on a few, mainly European species. However, subsequent studies (for example, Gavrilov and Trapeznikova 2007, Gavrilov-Zimin 2012, 2018a), including the present work, support the view of the mentioned authors (l.c.) that the main types of the reproductive system are characteristic of the higher taxa of scale insects (families, subfamilies, tribes).

\section{Material and methods}

Material was collected by the author in different years in Thailand, Laos, Malaysia and Indonesia (Sulawesi, Bali, New Guinea). The detailed collecting data are provided below for each species. All numbers with the letter " $\mathrm{K}$ " mean unique collecting numbers for both acetoethanol material and Canada balsam slides. All material is deposited at the Zoological Institute, Russian Academy of Sciences (ZIN RAS), St. Petersburg, Russia.

Both the method for the preparation of permanent morphological slides mounted with Canada balsam and the method of squashing the embryonic cells in lactoacetic orcein for chromosome studies were reported, for example, by Danzig and GavrilovZimin (2014).

All figures and photos, excluding the colour ones, were prepared by the author. The colour photos were prepared by the author with a kind help of D.A. Gapon.

\section{Results and discussion}

\section{Family Margarodidae s.l.}

\section{Steatococcus samaraius Morrison, 1927}

Figs 1a, 2

Material. K 922, Indonesia, Sulawesi, vicinity of Kendari, on twigs of undetermined bush, 10.XI.2011, I.A. Gavrilov-Zimin. K 1071, Malaysia, Borneo, Damai Peninsula, on inflorescences of palm tree (probably Areca catechu Linnaeus, 1753), 14.I.2013, I.A. Gavrilov-Zimin. 


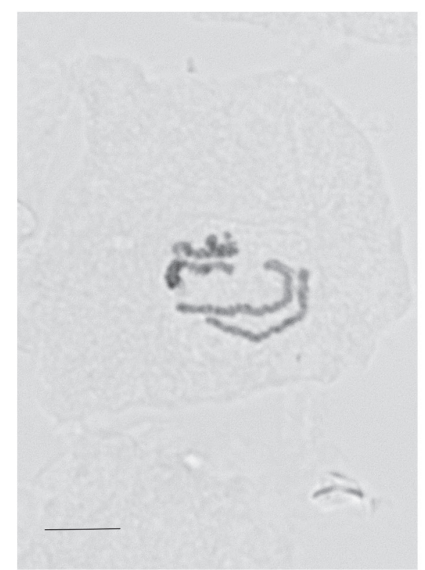

a

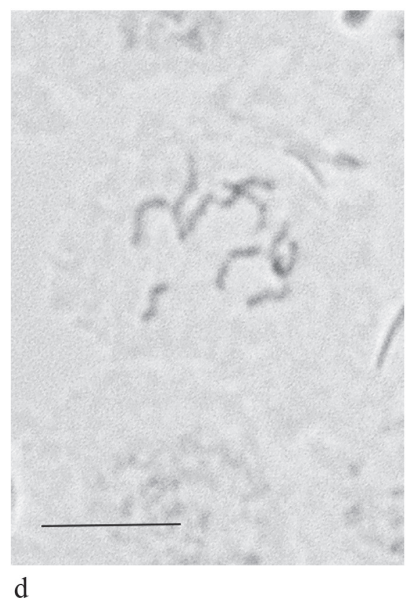

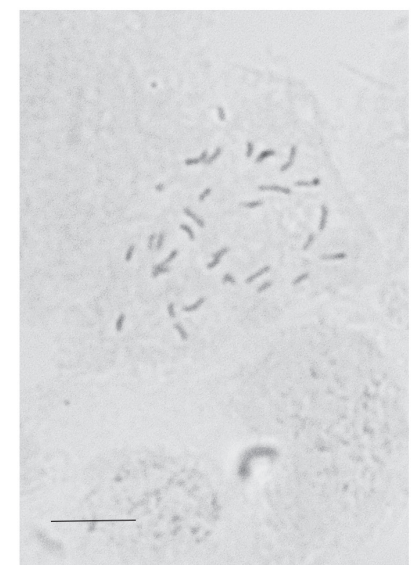

b

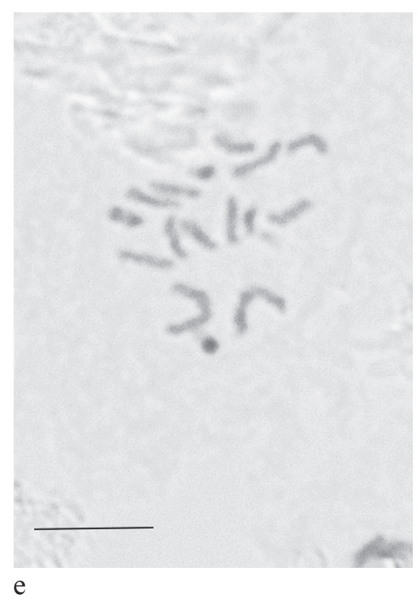

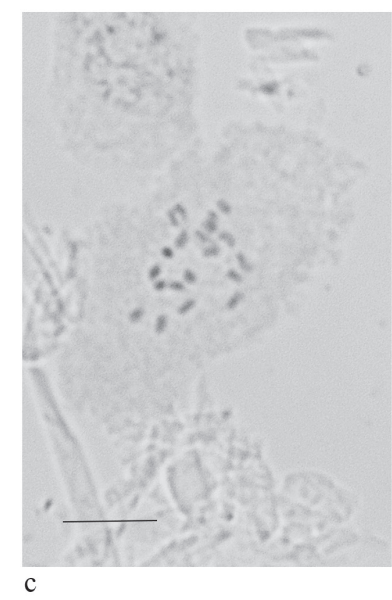

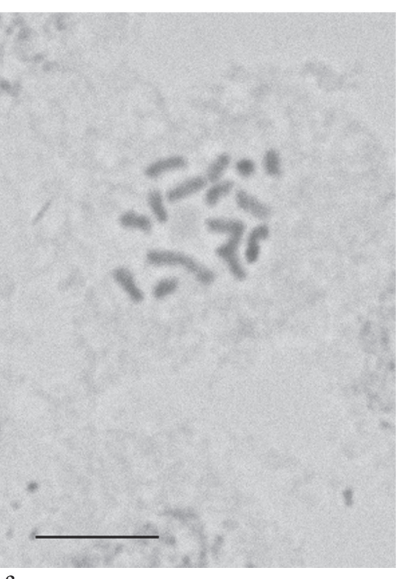

f

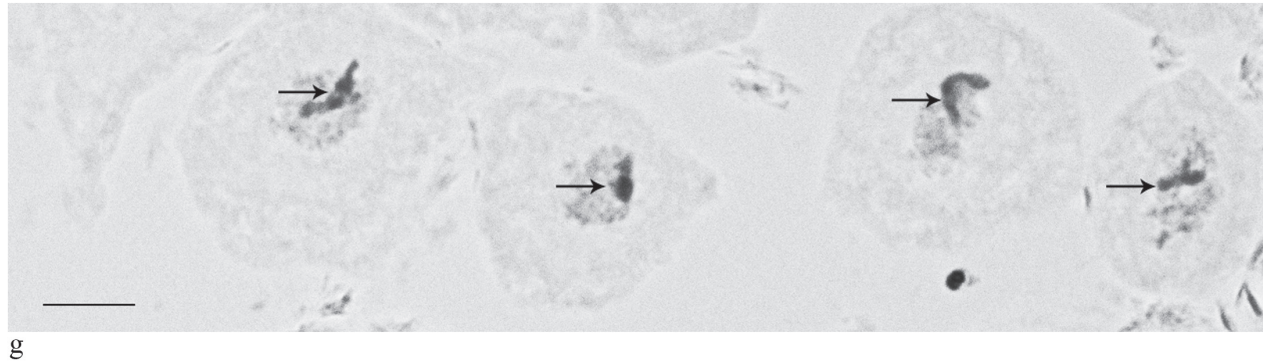

Figure I. Embryonic cells and chromosomes of the studied species (Margarodidae, Pseudococcidae, Eriococcidae). a Steatococcus samaraius $(2 \mathrm{n}=4) \mathbf{b}$ Antonina parazonata $(2 \mathrm{n}=30) \mathbf{c}$ A. vietnamensis $(2 \mathrm{n}=$ 20) d Mollicoccus guadalcanalanus $(2 \mathrm{n}=10)$ e Acanthococcus prope onukii $(2 \mathrm{n}=16) \mathbf{f}, \mathbf{g}$ Gossypariella siamensis $(2 \mathrm{n}=16)$. $\mathbf{g}$ Shows interphase cells of male embryos with a Lecanoid heterochromatinization of the paternal set of chromosomes (arrowed in each cell). Scale bars: $10 \mu \mathrm{m}$.

New data. $2 n=4$; hermaphroditism: the studied female-like ultimolarvae contain sperm bundles in the ovo-testicles. Early stages of embryogenesis (before anatrepsis) occur inside of ovary; then the eggs are laid in the marsupium, where the embryogen- 


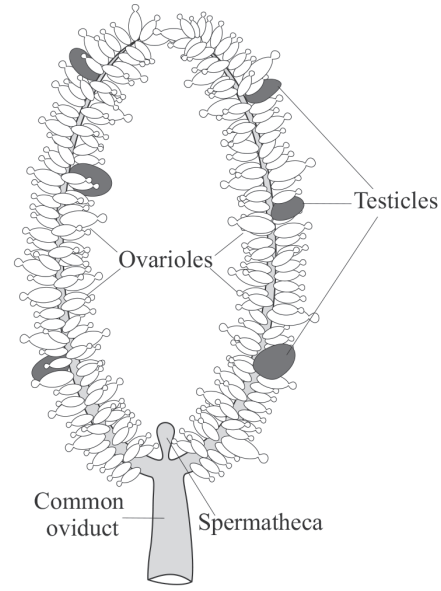

Steatococcus samaraius

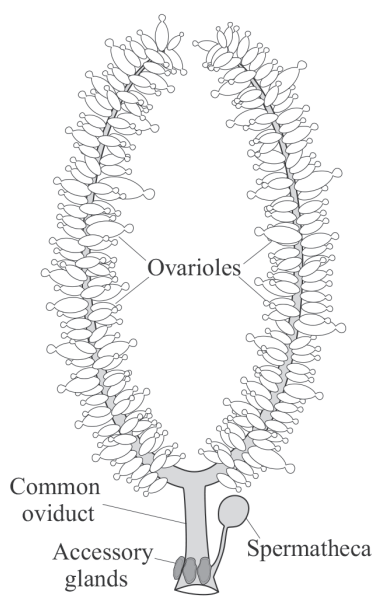

Antonina spp.

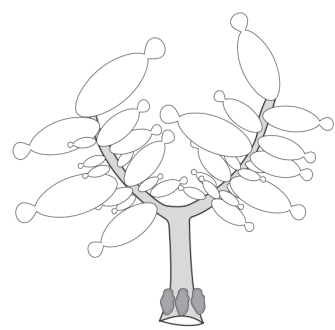

Geococcus satellitum

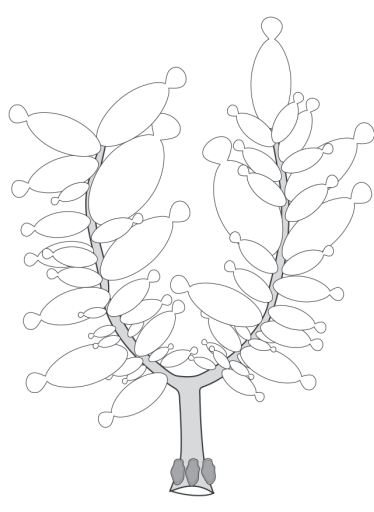

Mollicoccus guadalcanalanus

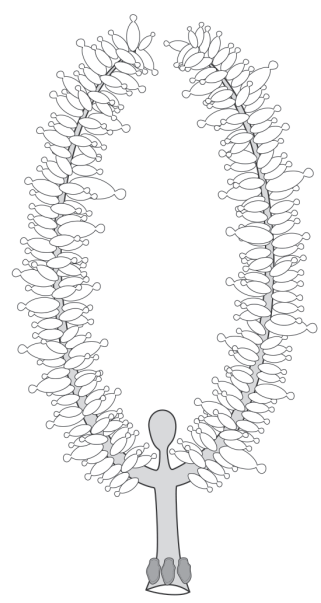

Acanthococcus prope onukii

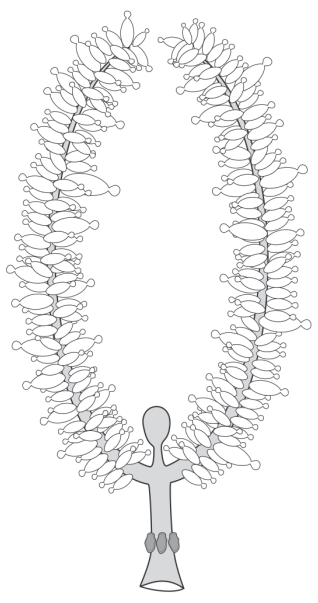

Gossypariella siamensis

Figure 2. General anatomy of the female (or female-like hermaphrodite in Steatococcus samaraius) reproductive system in the studied species (Margarodidae, Pseudococcidae, Eriococcidae).

esis ends. Hermaphroditic reproductive system is generally similar to the usual female system in bisexual species of scale insects, but contains testicular parts, located between numerous ovarioles (Fig. 2).

Comments. Hermaphroditism is an exceptionally rare phenomenon in Insecta (see, for example, Royer 1975). Up to now hermaphroditic species are known for sure only in the scale insect tribe Iceryini (Margarodidae: Monophlebinae) (HughesSchrader 1948, Gavrilov 2007, Gavrilov-Zimin 2018a). Previously, the presence of ovo-testicles in female-like diploid insects has been shown for Icerya bimaculata De Lotto, 1959 (Hughes-Shrader 1963), I. multicicatrices (Kondo \& Unruh, 2009) 
(Gavrilov-Zimin 2018a: 27, 190) and I. purchasi Maskell, 1879 (Schrader \& HughesSchrader 1926, Royer 1975). Closely related genus Steatococcus Ferris, 1921 (18 species), which differs from Icerya Signoret, 1876 ( 45 species) by the presence of peculiar marsupium, was previously almost unstudied in respect of cytogenetics and reproductive biology, excluding the only American species, S. tuberculatus Morrison, 1941. This species was investigated by Hughes-Schrader \& Ris (1941) who found that it had 2n $=4$ and reproduced bisexually with the appearance of haploid males via facultative parthenogenesis. Here, another species of the genus, $S$. samaraius, a widely distributed Oriental and Australasian pest, was studied and the same chromosome number, $2 \mathrm{n}$ $=4$, was discovered. However, males were totally absent in any populations of $S$. samaraius, inspected by me in the different countries of the Oriental region and seem to have never been reported in the literature. The preparation of the mature females and larvae expectedly revealed a hermaphroditic condition of the reproductive system of S. samaraius. Such a combination of hermaphroditism and haplo-diploidy in closely related species of one genus and even in different populations of the species (as is the case of Icerya purchasi; Schrader \& Hughes-Schrader 1926) is a peculiar feature of the tribe Iceryini (Hughes-Shrader 1963, Gavrilov-Zimin 2018a). Some authors (Unruh and Gullan 2007) do not consider Steatococcus as a separate genus and place its species either in the genus Icerya or in another related genus Crypticerya Cockerell, 1895. However, such approach leads to the total overlapping of the generic diagnostic characters and to the practical impossibility of assigning newly described species to a certain genus (see Gavrilov-Zimin 2018a: 174, 184, Gavrilov-Zimin and Stekolshikov 2018).

\section{Family Pseudococcidae}

\section{Antonina parazonata Williams, 2004}

Figs $1 b, 2$

Material. K 1533, Thailand, Pai, the road to Mae Yen Luang waterfalls, on twigs of bamboo, 13.XI.2019, I.A. Gavrilov-Zimin.

New data. $2 n=30$; bisexual reproduction with a Lecanoid heterochromatinization of paternal chromosomes in male embryos; complete ovoviviparity. Female reproductive system is similar to that of other studied mealybugs, i.e. with numerous ovarioles located on the paired oviducts, accessory glands attached to the proximal part of the common oviduct, and a spermatheca located at the same place as accessory glands (Fig. 2)

Comments. Special study of cytogenetics and reproductive biology of the genus Antonina Signoret, 1875 and other "legless mealybugs" was done recently (GavrilovZimin 2016). Nine species from 3 genera of legless mealybugs were considered in that paper based on original and literature data and a significant variation of chromosome number was shown: $2 \mathrm{n}=10,12,16,20,22+\mathrm{Bs}, 24,24+\mathrm{Bs}$, and 30. Antonina parazonata, studied here showed $2 \mathrm{n}=30$ as a species from the related monotypic genus Komodesia Gavrilov, 2016, namely, Komodesia circuliplurima Gavrilov, 2016. For the genus Antonina, such a high chromosome number was revealed for the first time. 
A. parazonata was previously known from the type localities in India only. It is the first record of this species for Thailand.

\section{Antonina vietnamensis Williams, 2004}

Figs 1c, 2

Material. K 1380, Laos, Pak Beng, on twigs of bamboo, 13.VI.2017, I.A. GavrilovZimin.

New data. 2n=20; bisexual reproduction with a Lecanoid heterochromatinization in male embryos; complete ovoviviparity. Female reproductive system is the same type as in $A$. parazonata (Fig. 2).

Comments. Antonina vietnamensis has the same chromosome number as a closely related Oriental species of the genus, A. diversiglandulosa Gavrilov, 2016.

A. vietnamensis was previously known from the type localities in Vietnam only. It is the first record of the species for Laos.

\section{Geococcus satellitum Williams, 2004}

Fig. 2

Material. K 1382, Laos, Pak Beng, on roots of dicotyledonous herb, 13.VI.2017, I.A. Gavrilov-Zimin.

New data. All studied embryos from 3 available females were unsuitable for chromosomal studies due to numerous yolk inclusions. Eggs are laid in loose ovisac at the stage of anatrepsis suggesting incomplete ovoviviparity. Female reproductive system is characterized by an extremely small number of ovarioles and the absence of a spermatheca (Fig. 2).

Comments. Up to now, the genus Geococcus Green, 1902 (14 species) has not been studied in terms of cytogenetics and reproductive biology. This is the case with most other related genera of tribe Rhizoecini (or group of the genus Rhizoecus Künckel d'Herculais, 1878). Diploid chromosome numbers, 8, 10, and 12, are known only for 5 species of Rhizoecus (Danzig \& Gavrilov-Zimin, 2015: 428-429); all these species are characterized by a Lecanoid genetic system and bisexual reproduction.

G. satellitum was previously known from the type localities in China and Thailand only. This is the first record of this species for Laos.

\section{Mollicoccus guadalcanalanus Williams, 1960}

Figs 1d, 2

Material. K 917, Indonesia, New Guinea, Manokwari, forest near the airport, on leaves of undetermined dicotyledonous herb, 8.XI. 2011, I.A. Gavrilov-Zimin. 
New data. $2 \mathrm{n}=10$; bisexual reproduction with a Lecanoid heterochromatinization in male embryos; eggs are laid in loose ovisac at stage of anatrepsis suggesting incomplete ovoviviparity. Female reproductive system is similar in general details to that of Geococcus satellitum (Fig. 2).

Comments. These are the first cytogenetic and reproductive data for monotypic Australasian genus Mollicoccus Williams, 1960. The diploid number 10 is considered a modal chromosome number for the family Pseudococcidae as a whole (Nur 1980, Gavrilov 2007, Gavrilov-Zimin et al. 2015).

\section{Family Eriococcidae}

\section{Acanthococcus prope onukii (Kuwana, 1902)}

Figs 1e, 2

Material. K 1513, Thailand, Chiang Mai, slope of Doi Suthep Mt. near the University, on leaves of bamboo, 8.XI.2019, I.A. Gavrilov-Zimin.

New data. $2 n=16$; bisexual reproduction with a Lecanoid heterochromatinization in male embryos. Eggs are laid in dense wax ovisac at the stage of anatrepsis, i.e. incomplete ovoviviparity is characteristic of the species. Female reproductive system consists of a spermatheca attached at the junction of the oviducts and accessory glands attached at the base of a common oviduct (Fig. 2).

Comments. Only two species of the large genus Acanthococcus Signoret, 1875 have been previously studied cytogenetically, i.e. European A. agropyri (Borchsenius, 1949) and $A$. insignis (Newstead, 1891), both with $2 \mathrm{n}=16$ (Gavrilov 2004, 2007). [Nota bene! The studied specimens differ from a common Acanthococcus onukii (=Anophococcus onukii) in the conical setae with blunt apices. The generic name Anophococcus Balachowsky, 1954 is considered here as a synonym of Acanthococcus (synonymized by Danzig 1980: 205)].

\section{Gossypariella siamensis (Takahashi, 1942)}

Figs $1 \mathrm{f}-\mathrm{g}, 2$, 5a

Material. K 1521, Thailand, Chiang Mai, city street near the University, on branches and twigs of an undetermined dicotyledonous tree, probably Ficus sp., 9.XI.2019, I.A. Gavrilov-Zimin.

New data. $2 \mathrm{n}=16$; bisexual reproduction with a Lecanoid heterochromatinization in male embryos. Complete ovoviviparity. Female reproductive system is similar with that in the previous species, but accessory glands are located in the middle part of the common oviduct (Fig. 2).

Comments. The genus Gossypariella Borchsenius, 1960 includes 4 species distributed in the Oriental region. G. siamensis is the first species of the genus studied cytogenetically. 


\section{Family Coccidae}

\section{Coccus viridis (Green, 1889)}

Figs 3a, 4

Material. K 939, Indonesia, Bali, mountain forest above Lake Buyan, about $1200 \mathrm{~m}$ altitude, on leaves of an undetermined tree, 13.XI. 2011, I.A. Gavrilov-Zimin.

New data. $2 \mathrm{n}=18$; there is no heterochromatinization (and thus no Lecanoid system) in all 50 studied embryos from 3 females, no sperm in spermathecae and no males in the studied population; so, the thelytocous reproduction is characteristic of this species. Complete ovoviviparity. Female reproductive system is of the usual for the soft scales type (Fig. 4).

Comments. The type species of the genus, Coccus hesperidum Linnaeus, 1758, shows $2 \mathrm{n}=14$ and different variants of parthenogenesis (Thomsen 1927, 1929, Nur 1979), whereas two other studied species, C. longulus (Douglas, 1887) and Coccus sp., were reported by Moharana (1990) as having $2 \mathrm{n}=18$, but without any comments on genetic system and reproductive peculiarities. All other (more than 110) species of the genus Coccus Linnaeus, 1758, are still unstudied cytogenetically.

\section{Discochiton expansum (Green, 1896)}

Figs $3 \mathrm{~b}, 4$

Material. K 1121, Thailand, Malay Peninsula, Khao Lak, forest above the city, on leaves of an undetermined bush, 8.XI. 2013, I.A. Gavrilov-Zimin.

New data. $2 n=18$; bisexual reproduction with a Lecanoid heterochromatinization in male embryos. Complete ovoviviparity. Female reproductive system has the usual structure, but accessory glands are poorly visible (Fig. 4).

Comments. The recently erected genus Discochiton Hodgson \& Williams, 2018 comprises 21 species, and $D$. expansum is the first species of the genus studied cytogenetically.

\section{Drepanococcus chiton (Green, 1909)}

Fig. 4

Material. K 864, Indonesia, New Guinea, vicinity of Jayapura, Entrop, on stem of a dicotyledonous herb, 30.X. 2011, I.A. Gavrilov-Zimin.

New data. There were no embryonic cells suitable for chromosomal analysis in the available material. The reproduction is bisexual with a Lecanoid heterochromatinization in male embryos. All studied females contained embryos at early stages of embryogenesis (up to anatrepsis). Female reproductive system has the usual structure (Fig. 4).

Comments. The only other species of the genus, D. cajani (Maskell, 1891), was previously studied cytogenetically by Moharana (1990), who reported $2 \mathrm{n}=18$ with no other comments on the species. 


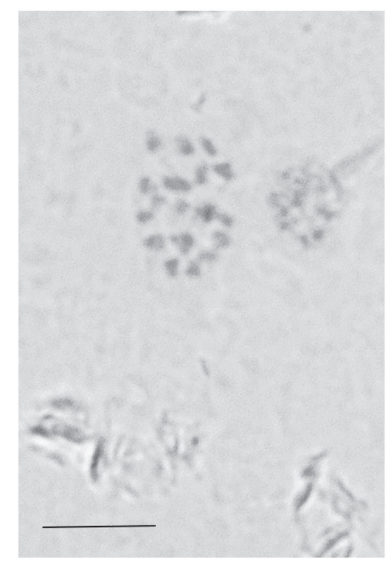

a

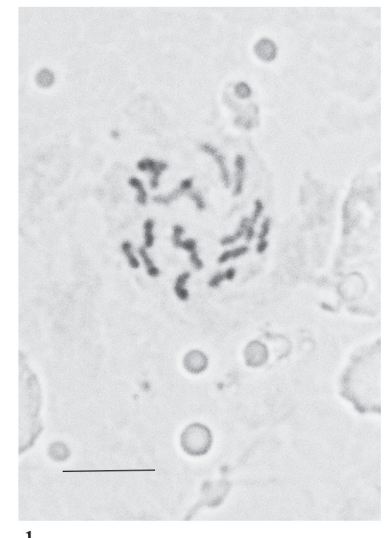

d

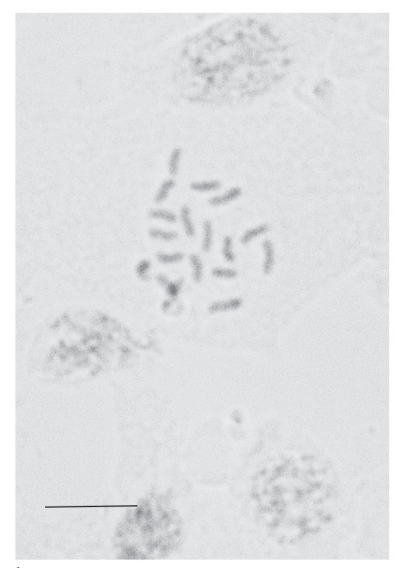

b

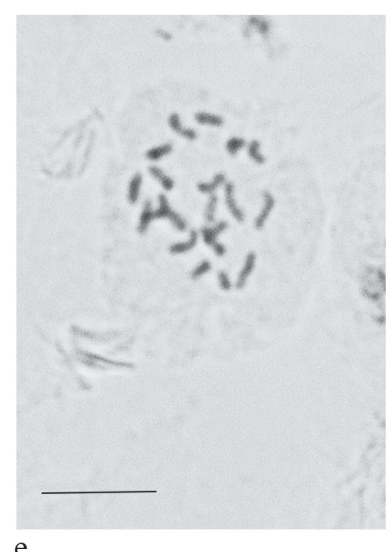

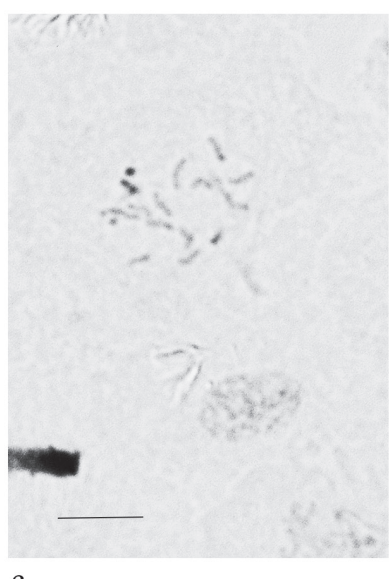

c

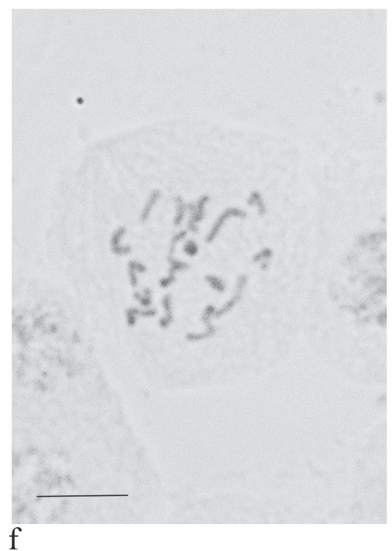

Figure 3. Embryonic cells and chromosomes of the studied species (Coccidae). a Coccus viridis ( $\mathrm{n}=$ 18) b Discochiton expansum $(2 \mathrm{n}=18)$ c Luzulaspis australis $(2 \mathrm{n}=18)$ d Megalocryptes buteae $(2 \mathrm{n}=18)$ e Megapulvinaria maxima $(2 \mathrm{n}=20) \mathbf{f}$ Saccharolecanium krugeri $(2 \mathrm{n}=18)$. Scale bars: $10 \mu \mathrm{m}$.

\section{Luzulaspis australis (Maskell, 1894)}

Figs 3c, 4

Material. K 861, Indonesia, New Guinea, vicinity of Jayapura, Entrop, under leaf sheathes of a Poaceae grass, 30.X. 2011, I.A. Gavrilov-Zimin.

New data. $2 \mathrm{n}=18$; bisexual reproduction with a Lecanoid heterochromatinization in male embryos. The eggs are laid in a long wax ovisac at the stage of late anatrepsis; i.e. incomplete ovoviviparity is characteristic of the species. Female reproductive system has the usual structure (Fig. 4).

Comments. The genus Luzulaspis Cockerell, 1902 comprises about 25 species, but only one of them, European L. dactylis Green, 1928, has been thus far studied cytogenetically (Gavrilov 2004). This species was found to have $2 \mathrm{n}=18$ and a bisexual reproduction with a Lecanoid heterochromatinization as well as presently studied Australasian L. australis. 


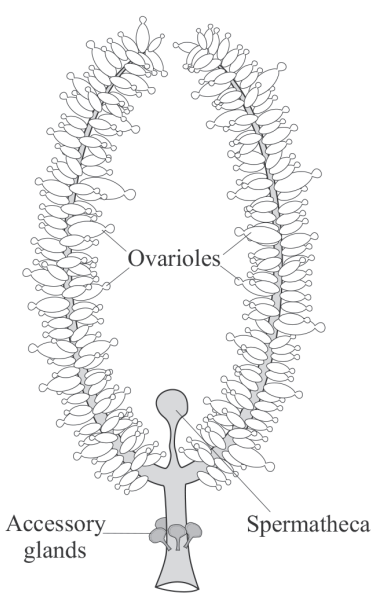

Coccus viridis,

Drepanococcus chiton

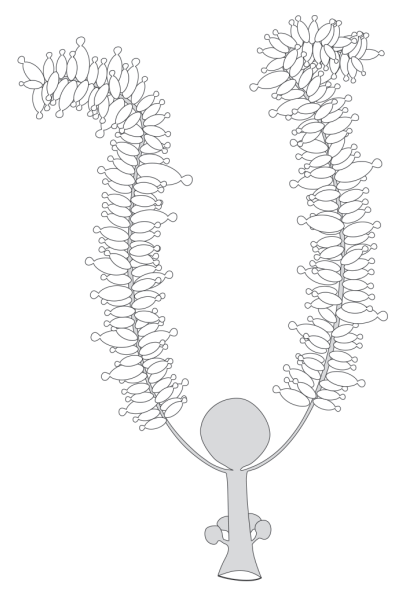

Megalocryptes buteae

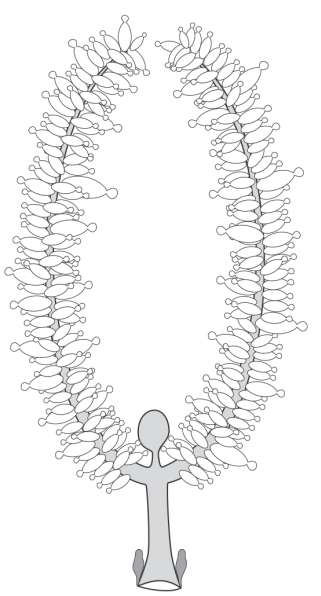

Discochiton expansum

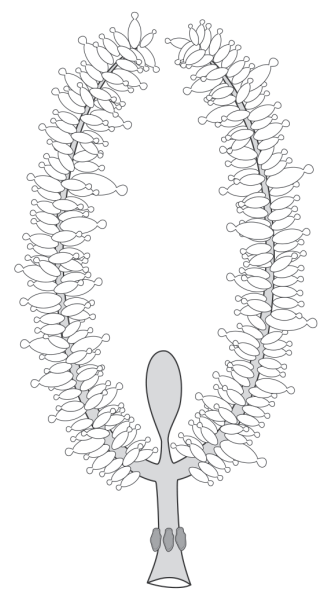

Saccharolecanium krugeri

Figure 4. General anatomy of the female reproductive system in the studied species (Coccidae).

\section{Megalocryptes buteae Takahashi, 1942}

Figs 3d, 4, $5 \mathrm{c}$

Material. K 1536, Thailand, Pai, on twigs of an undetermined dicotyledonous tree, 13.XI.2019, I.A. Gavrilov-Zimin.

New data. $2 n=18$; there is no heterochromatinization in all 72 studied embryos from 3 females, no sperm in spermathecae and no males in the population suggesting thus thelytokous reproduction. Female reproductive system is distinguished by unusually long and thin lateral oviducts (Fig. 4). Cleavage divisions in the egg start just prior to oviposition.

Comments. These are the first cytogenetic and reproductive data for the small Oriental genus Megalocryptes Takahashi, 1942 which comprises two species only. 
a

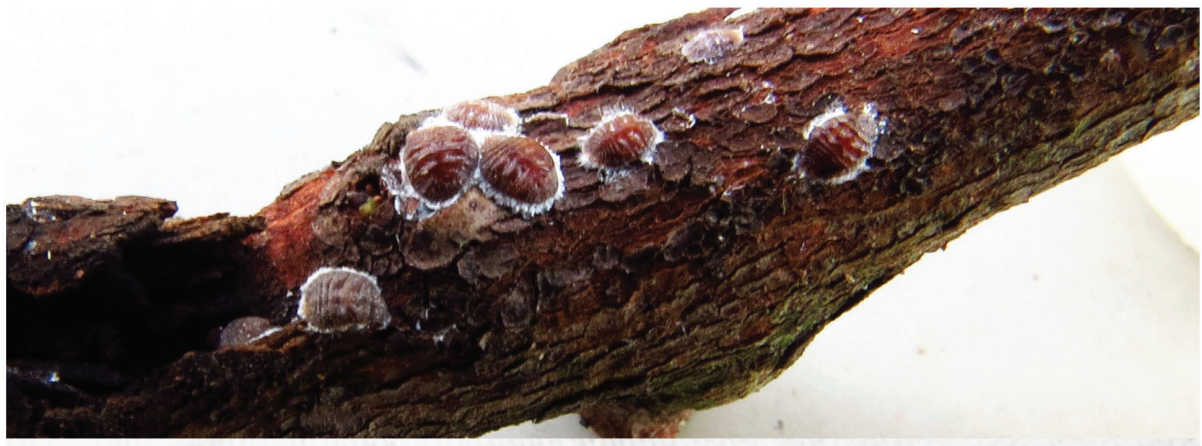

b

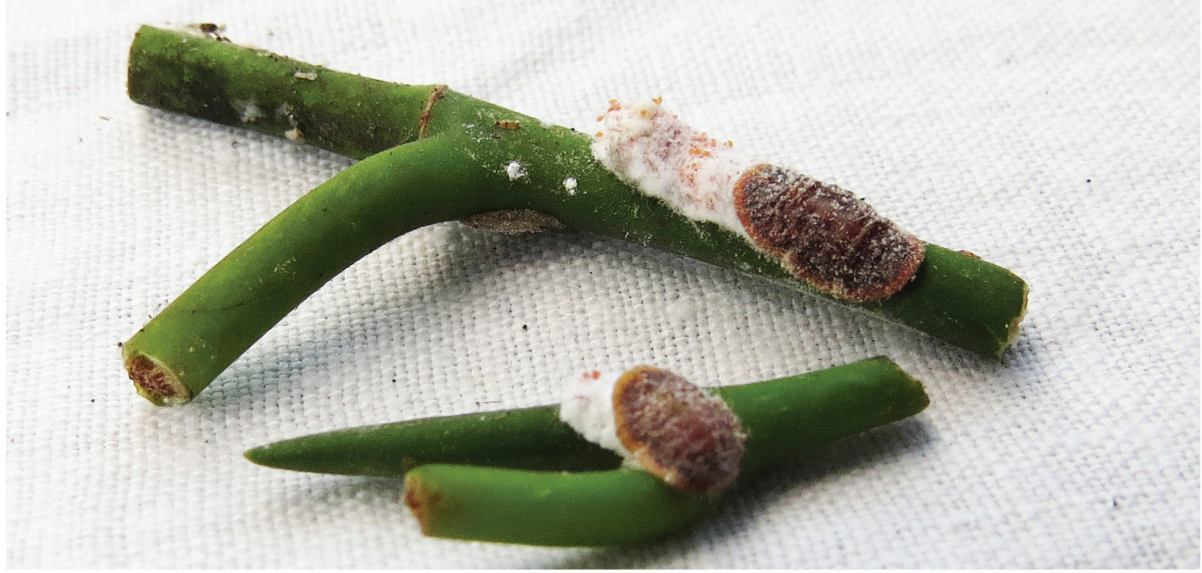

c

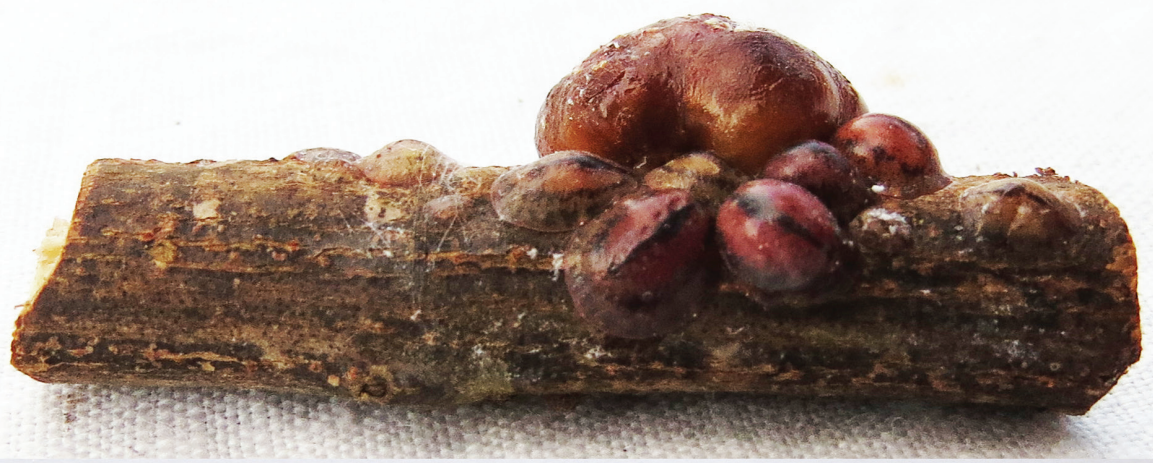

d

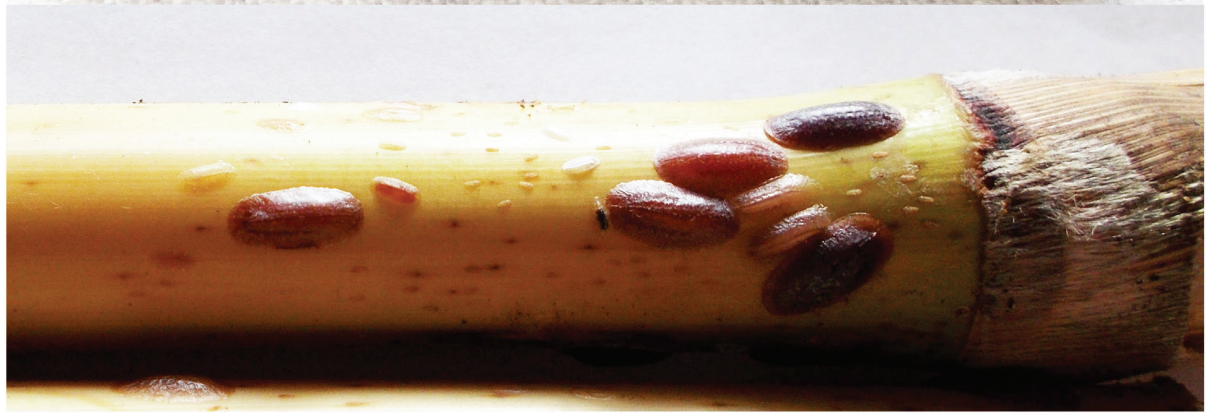

Figure 5. Females of some species on twigs of host plants. a Gossypariella siamensis b Megapulvinaria maxima c Megalocryptes buteae (with a colony of Kerria sp. at the background) d Saccharolecanium krugeri. 


\section{Megapulvinaria maxima (Green, 1904)}

Figs 3e, 4, 5b

Material. K 1531, Thailand, Pai, on leaves and twigs of an undetermined dicotyledonous tree, 13.XI.2019, I.A. Gavrilov-Zimin.

New data. $2 \mathrm{n}=20$; bisexual reproduction with a Lecanoid heterochromatinization in male embryos. Incomplete ovoviviparity: embryogenesis (until the late anatrepsis) partially occurs inside of the mother's body. Female reproductive system has the usual structure (Fig. 4).

Comments. Different European members of the tribe Pulvinariini have been previously studied cytogenetically (Gavrilov 2007, Gavrilov and Trapeznikova 2008). Four Oriental species from the genera Chloropulvinaria Borchsenius, 1952, Pseudopulvinaria Atkinson, 1889 and Pulvinaria Targioni Tozzetti, 1866 were studied by Moharana (1990), who reported chromosome numbers with no comments or details. $M$. maxima is the first species of the genus Megapulvinaria Yang, 1982 studied in terms of chromosome number; the kartotype $2 \mathrm{n}=20$ is found for the first time in the tribe Pulvinariini in general.

\section{Saccharolecanium krugeri (Zehntner, 1897)}

Figs 3f, 4, 5d

Material. K 1368, Thailand, vicinity of Chiang Rai, forest above the Mae Fah Luang University, under the leaf sheathes of ?Saccharum sp., 8.VI.2017, I.A. Gavrilov-Zimin.

New data. $2 \mathrm{n}=18$; bisexual reproduction with a Lecanoid heterochromatinization in male embryos. Complete ovoviviparity. Female reproductive system has the usual structure (Fig. 4).

Comments. These are the first cytogenetic and reproductive data for the small Oriental genus Saccharolecanium Williams, 1980, which comprises two species only. S. krugeri is noted here for the first time for the territory of Thailand.

\section{Acknowledgements}

Financial support for this study was provided by the research grant no. 19-5418002 from the Russian Foundation for Basic Research. The part of the material was prepared for the collection of the Zoological Institute, Russian Academy of Sciences according to the state projects nos. AAAA-A19-119020790106-0 and AAAAA19-119020690101-6. Expedition expenses of different years were partly covered by Percy Sladen Memorial Fund. The author thanks D.A. Gapon for his help with the photographing of some studied insects in the nature. 


\section{References}

Danzig EM (1980) Koktsydy Dal'nego Vostoka SSSR (Homoptera, Coccinea) s analizom filogenii koktsyd mirovoy fauny. Leningrad, 367 pp. [In Russian] [English Edition: Danzig EM (1986) Coccids of the Far-Eastern USSR (Homoptera: Coccinea). Phylogenetic analysis of coccids in the world fauna. New Delhi, 450 pp.]

Danzig EM, Gavrilov-Zimin IA (2014) Palaearctic mealybugs (Homoptera: Coccinea: Pseudococcidae). Part 1. Subfamily Phenacoccinae. St. Petersburg, 678 pp. (Fauna of Russia and neighbouring countries. New series, № 148. Insecta: Hemiptera: Arthroidignatha).

Danzig EM, Gavrilov-Zimin IA (2015) Palaearctic mealybugs (Homoptera: Coccinea: Pseudococcidae). Part 2. Subfamily Pseudococcidae. St. Petersburg, 619 pp. (Fauna of Russia and neighbouring countries. New series, № 149. Insecta: Hemiptera: Arthroidignatha). https://doi.org/10.31610/zsr/2015.24.2.236

De Marzo L, Romano V, Tranfaglia A (1990) Types of the reproductive system in some scale insects (Homoptera: Coccoidea). Proceedings of the VI International Symposium of Scale Insect Studies. Krakow, August 6-12, 1990, 2. Krakow, 41-46.

Gavrilov IA (2004) Taxonomic and cytogenetic studies of scale insects (Homoptera: Coccinea) of European Russia. Proceedings of the Zoological Institute RAS 300: 77-82.

Gavrilov IA (2007) A catalogue of chromosome numbers and genetic systems of scale insects (Homoptera: Coccinea) of the world. Israel Journal of Entomology 37: 1-45.

Gavrilov-Zimin IA (2011) New cytogenetic data for some Palaearctic species of scale insects (Homoptera: Coccinea) with karyosystematic notes. Comparative Cytogenetics 5(5): 375390. https://doi.org/10.3897/compcytogen.v5i5.2116

Gavrilov-Zimin IA (2012) A contribution to the taxonomy, cytogenetics and reproductive biology of the genus Aclerda Signoret (Homoptera, Coccinea, Aclerdidae). Comparative Cytogenetics 6(4): 389-395. https://doi.org/10.3897/compcytogen.v6i4.4320

Gavrilov-Zimin IA (2016) Cytogenetic and taxonomic studies of some legless mealybugs (Homoptera: Coccinea: Pseudococcidae). Comparative Cytogenetics 10(4): 587-601. https://doi.org/10.3897/compcytogen.v10i4.10503

Gavrilov-Zimin IA (2017) Contribution to the cytogenetics of Kuwaniini scale insects (Homoptera, Coccinea, Margarodidae s.1.). Comparative Cytogenetics 11(4): 659-663. https:// doi.org/10.3897/CompCytogen.v11i4.20168

Gavrilov-Zimin IA (2018a) Ontogenesis, morphology and higher classification of archaecococcids (Homoptera: Coccinea: Orthezioidea). Zoosystematica Rossica (Supplementum 2). 260 pp. https://doi.org/10.31610/zsr/2018.supl.2.1

Gavrilov-Zimin IA (2018) First illustration of chromosomes and genetic system of Lecanodiaspidinae (Homoptera: Coccinea: Asterolecaniidae s.l.). Comparative Cytogenetics 12(3): 439-443. https://doi.org/10.3897/CompCytogen.v12i3.29648

Gavrilov IA, Kuznetsova VG (2007) On some terms in scale insects cytogenetics and reproductive biology (Homoptera: Coccinea). Comparative Cytogenetics 1(2): 169-174. 
Gavrilov-Zimin IA, Stekolshikov AV (2018) A new species of the genus Steatococcus Ferris, 1921 (Homoptera: Coccinea: Margarodidae) with some additions to fauna of Republic of Mali. Entomological Review 98(7): 865-867. https://doi.org/10.1134/S0013873818070060

Gavrilov-Zimin IA, Stekolshikov AV, Gautam DC (2015) General trends of chromosomal evolution in Aphidococca (Insecta, Homoptera, Aphidinea + Coccinea). Comparative Cytogenetics 9(3): 335-422. https://doi.org/10.3897/CompCytogen.v9i3.4930

Gavrilov IA, Trapeznikova IV (2007) Karyotypes and reproductive biology of some mealybugs (Homoptera: Coccinea: Pseudococcidae). Comparative Cytogenetics 1(2): 139-148.

Gavrilov IA, Trapeznikova IV (2008) Cytogenetic studies of European Pulvinariini (Homoptera: Coccinea). Comparative Cytogenetics 2(2): 123-131.

Gavrilov IA, Trapeznikova IV (2010) Karyotypes of six previously unstudied European mealybugs (Homoptera: Pseudococcidae). Comparative Cytogenetics 4(2): 203-205. https:// doi.org/10.3897/compcytogen.v4i2.44

Hughes-Schrader S (1948) Cytology of coccids (Coccoidea-Homoptera). Advances in Genetics 2: 127-203. https://doi.org/10.1016/S0065-2660(08)60468-X

Hughes-Schrader S (1963) Hermaphroditism in an African coccid, with notes on other Margarodids (Coccoidea-Homoptera). Journal of Morphology 113: 173-184. https://doi. org/10.1002/jmor.1051130205

Hughes-Schrader S, Ris H (1941) The diffuse spindle attachment of coccids, verified by the mitotic behavior of induced chromosome fragments. Journal of Experimental Zoology 87: 429-456. https://doi.org/10.1002/jez.1400870306

Moharana S (1990) Cytotaxonomy of coccids (Homoptera: Coccoidea). Proceedings of the VI International Symposium of Scale Insect Studies. Krakow, August 6-12, 1990, 2. Krakow, 47-54.

Nur U (1979) Gonoid thelytoky in soft scale insects (Coccidae: Homoptera). Chromosoma (Berlin) 72: 89-104. https://doi.org/10.1007/BF00286431

Nur U (1980) Evolution of unusual chromosome systems in scale insects (Coccoidea: Homoptera). In: Blackman RL, Hewitt GM, Ashburner M (Eds) Insect Cytogenetics. London, 97-117.

Royer M (1975) Hermaphroditism in Insects. Studies on Icerya purchasi. In: Reinboth R (Ed.) Intersexuality in the Animal Kingdom. Springer, Berlin, Heidelberg, 135-145. https://doi. org/10.1007/978-3-642-66069-6_14

Schrader F, Hughes-Schrader S (1926) Haploidy in Icerya purchasi. Zeitschrift für Wissenschaftliche Zoologie 128: 182-200.

Thomsen M (1927) Studien über die partenogenese bei einigen Cocciden und Aleyrodiden. Zeitschrift für Zellforschung und Mikroskopische Anatomie 5(1/2): 1-116. https://doi. org/10.1007/BF00398903

Thomsen M (1929) Sex-determination in Lecanium. In: Jordan K, Horn W (Eds) Fourth International Congress of Entomology, Ithaca, August 1928, 2, Ithaca, 18-24.

Unruh CM, Gullan PJ (2007) Molecular data reveal convergent reproductive strategies in iceryine scale insects (Hemiptera: Coccoidea: Monophlebidae), allowing the re-interpretation of morphology and a revised generic classification. Systematic Entomology 33: 8-50. https://doi.org/10.1111/j.1365-3113.2007.00404.x 